\title{
New criteria for oscillation of nonlinear neutral differential equations
}

\section{Osama Moaaz ${ }^{1 *}$ (D)}

\section{"Correspondence:}

o moaaz@mans.edu.eg

${ }^{1}$ Department of Mathematics,

Faculty of Science, Mansoura

University, Mansoura, Egypt

\section{Abstract}

The aim of this work is to offer sufficient conditions for the oscillation of neutral differential equation second order

$$
\left(r(t)\left[(y(t)+p(t) y(\tau(t)))^{\prime}\right]^{\gamma}\right)^{\prime}+f(t, y(\sigma(t)))=0,
$$

where $\int^{\infty} r^{-1 / \gamma}(s) \mathrm{d} s=\infty$. Based on the comparison with first order delay equations and by employ the Riccati substitution technique, we improve and complement a number of well-known results. Some examples are provided to show the importance of these results.

MSC: $34 \mathrm{C} 10 ; 34 \mathrm{~K} 11$

Keywords: Neutral delay differential equations; Oscillation criteria

\section{Introduction}

In this paper, we are interested in finding the sufficient conditions which ensure that the solutions of the equation

$$
\left(r(t)\left[(y(t)+p(t) y(\tau(t)))^{\prime}\right]^{\gamma}\right)^{\prime}+f(t, y(\sigma(t)))=0
$$

are oscillatory, where $t \geq t_{0}$. Throughout this work, we suppose that:

$\left(\boldsymbol{\Pi}_{1}\right) \gamma=a / b$ and $a, b$ are odd positive integers;

$\left(\boldsymbol{\Pi}_{2}\right) r, p \in C\left(\left[t_{0}, \infty\right), \mathbb{R}\right), 0 \leq p(t)<1, r(t)>0$,

$$
\eta(t, s):=\int_{s}^{t} r^{-1 / \gamma}(u) \mathrm{d} u, \quad s \leq t,
$$

and $\eta\left(\infty, t_{0}\right)=\infty$;

$\left(\boldsymbol{\Pi}_{3}\right) \tau, \sigma \in C\left(\left[t_{0}, \infty\right), \mathbb{R}\right), \tau(t) \leq t, 0<\sigma(t) \leq t$, and $\lim _{t \rightarrow \infty} \tau(t)=\lim _{t \rightarrow \infty} \sigma(t)=\infty$;

$\left(\boldsymbol{\Pi}_{4}\right) f(t, y) \in C\left(\left[t_{0}, \infty\right) \times \mathbb{R}, \mathbb{R}\right), y f(t, y)>0$ for all $y \neq 0$, there exists $q \in C\left(\left[t_{0}, \infty\right),(0, \infty)\right)$ such that $|f(t, y)| \geq q(t)|y|^{\beta}$ and $\beta$ is a quotient of odd positive integers.

Here, we define

$$
u(t):=(y+p y(\tau))(t) .
$$

(c) The Author(s) 2019. This article is distributed under the terms of the Creative Commons Attribution 4.0 International License (http://creativecommons.org/licenses/by/4.0/), which permits unrestricted use, distribution, and reproduction in any medium, provided you give appropriate credit to the original author(s) and the source, provide a link to the Creative Commons license, and indicate if changes were made. 
For a solution of (1.1), we propose a nontrivial function $y \in C\left(\left[t_{y}, \infty\right), \mathbb{R}\right), t_{y} \geq t_{0}$, which satisfies $(1.1)$ on $\left[t_{y}, \infty\right)$, and has the property $u(t)$ and $r(t)\left(u^{\prime}(t)\right)^{\gamma}$ are continuously differentiable for $t \in\left[t_{y}, \infty\right)$. We only focus on solutions of (1.1) which exist on $\left[t_{0}, \infty\right)$ and satisfy $\sup \left\{|y(t)|: t_{y} \leq t\right\}>0$ for every $t \geq t_{y}$. If $y$ is neither eventually positive nor eventually negative, then $y(t)$ is called oscillatory, otherwise it is called non-oscillatory.

Differential equations with neutral argument have interesting applications in problems of real world life. In the networks containing lossless transmission lines, the neutral differential equations appear in the modeling of these phenomena as is the case in high-speed computers. In addition, second order neutral equations appear in the theory of automatic control and in aeromechanical systems, in which inertia plays an important role. Moreover, second order delay equations play an important role in studying vibrating masses attached to an elastic bar, as the Euler equation, see [1, 2, 7]. One area of active research in recent times is to study the sufficient criterion for oscillation of delay differential equations, see [1-30].

Over this decade, a great amount of work has been done on development the oscillation theory of second order delay and advanced equations, see [3, 4, 9, 11-14, 16, 17, 22], and the oscillation theory of higher order delay equations, see [8, 10, 18, 19, 21, 24-26, 29].

In particular, by using the comparison technique, the equation

$$
\left(r\left[u^{\prime}\right]^{\gamma}\right)^{\prime}(t)+\left(q y^{\beta}(\sigma)\right)(t)=0
$$

have been studied by Baculikova and Dzurina in [6] when $\gamma \geq \beta, \sigma(t)$ and $\tau(t)$ are nondecreasing, $\tau(\sigma(t))=\sigma(\tau(t))$. By using the Riccati transformation technique, in [23, 28, 30], the oscillatory properties of solutions of the equation

$$
\left(r\left|u^{\prime}\right|^{\gamma-1} u^{\prime}\right)^{\prime}(t)+\left(q|y(\sigma)|^{\beta-1} y(\sigma)\right)(t)=0
$$

have been considered. Liu et al. [23] studied the oscillation properties for (1.4) under the conditions $\gamma \geq \beta, r^{\prime}(t)>0$, and $\sigma^{\prime}(t)>0$. Zeng et al. [30] used the technique of Riccati transformation to obtain oscillation conditions for (1.4), which improves the results in [23]. Under a more general case, namely for all $\gamma>0$ and $\beta>0$, Wu et al. [28] studied the oscillation criteria of equation (1.4).

The purpose of this work is to contribute to the development of the oscillation theory of second order nonlinear equations with delay argument. Firstly, by using comparison theorems that compare the second order equation with first order delay equation, we obtain two different conditions to ensure oscillation of (1.1) when $\gamma<\beta$ and $\gamma>\beta$. The results of this part improve and complement the results in [6].

Secondly, we present a new result for oscillation of (1.1) by using the technique of Riccati transformation, which improves the related results reported in [23, 28]. In order to show the importance of our results, we introduce two examples and compare the results in this paper with the previous results.

We will need the following two lemmas in the next parts.

Lemma 1.1 ([5, Lemma 3]) If the function $w$ satisfies $w>0, w^{\prime}>0$, and $w^{\prime \prime} \leq 0$ for $t \geq t_{0}$, then there exists $t_{\mu} \geq t_{0}$ such that

$$
w(\sigma)(t) \geq \mu \frac{1}{t} \sigma(t) w(t)
$$


for all $\mu \in(0,1)$.

Lemma 1.2 Assume that $\Psi(s):=k s-l s^{1+1 / \gamma}$, where $k$ and $l$ are real constants, $l>0$ and $\gamma$ is defined as $\left(\Pi_{1}\right)$. Then we have

$$
\Psi(s) \leq \max _{s \in \mathbb{R}} \Psi(s)=\frac{1}{\gamma}\left(\frac{\gamma}{\gamma+1}\right)^{\gamma+1} k^{\gamma+1} l^{-\gamma}
$$

\section{Main results}

Throughout this paper, we will be employing the following notation:

$$
\begin{aligned}
& G(t):=q(t)(1-p(\sigma(t)))^{\beta}, \\
& \Theta(t):=\eta\left(t, t_{0}\right)+\frac{\mu^{\beta}}{\gamma} \int_{t_{0}}^{t} \frac{\sigma^{\beta}(\nu)}{v^{\beta}} \rho(v) \eta^{1+\gamma}\left(v, t_{0}\right) G(v) \mathrm{d} \nu, \\
& \widehat{\Theta}(t):=\eta\left(t, t_{1}\right)+\frac{C^{\beta-\gamma}}{\gamma} \int_{t_{1}}^{t} \eta\left(\nu, t_{1}\right) \eta^{\gamma}\left(\sigma(v), t_{1}\right) G(v) \mathrm{d} v,
\end{aligned}
$$

and

$$
\rho(t):= \begin{cases}\lambda_{1} & \text { if } \gamma<\beta ; \\ 1 & \text { if } \gamma=\beta ; \\ \lambda_{2} \eta^{\beta-\gamma}\left(t, t_{0}\right) & \text { if } \gamma>\beta,\end{cases}
$$

where $\mu \in(0,1)$ and $C, \lambda_{1}$, and $\lambda_{2}$ are positive real constants.

Theorem 2.1 Assume that $r^{\prime}(t) \geq 0$. If every solution of

$$
v^{\prime}(t)+G(t) \Theta^{\beta}(\sigma(t)) v^{\beta / \gamma}(\sigma(t))=0
$$

oscillates for any $\lambda_{1}, \lambda_{2}>0$, then every solution of (1.1) oscillates.

Proof Assume the contrary and suppose that equation (1.1) has a nonoscillatory solution $y$ on $\left[t_{0}, \infty\right)$. Now, we suppose, without loss of generality, that $y>0, y(\tau)>0$, and $y(\sigma)>0$ for $t \geq t_{1} \geq t_{0}$. Hence, we find $u(t)>0$ and $\left(r(t)\left(u^{\prime}(t)\right)^{\gamma}\right)^{\prime} \leq 0$ for $t \geq t_{1}$. From [6, Lemma 3], we have that $u^{\prime}(t)>0$ for $t \geq t_{1}$. From definition (1.2), we get

$$
\begin{aligned}
y(t) & =u(t)-p(t) y(\tau(t)) \\
& \geq u(t)-p(t) u(\tau(t)) \\
& \geq(1-p(t)) u(t) .
\end{aligned}
$$

From (1.1), $\left(\Pi_{4}\right)$, and $(2.2)$, we obtain

$$
\begin{aligned}
\left(r(t)\left(u^{\prime}(t)\right)^{\gamma}\right)^{\prime} & =-f(t, y(\sigma(t))) \leq-q(t) y^{\beta}(\sigma(t)) \\
& \leq-G(t) u^{\beta}(\sigma(t)) .
\end{aligned}
$$


Since $\left(r(t)\left(u^{\prime}(t)\right)^{\gamma}\right)^{\prime} \leq 0$, we see that the function $U(t):=r^{1 / \gamma}(t) u^{\prime}(t)$ is nonincreasing, and hence

$$
\begin{aligned}
u(t) & =u\left(t_{1}\right)+\int_{t_{1}}^{t} u^{\prime}(v) \mathrm{d} v=u\left(t_{1}\right)+\int_{t_{1}}^{t} \frac{1}{r^{1 / \gamma}(v)} U(v) \mathrm{d} v \\
& \geq U(t) \int_{t_{1}}^{t} \frac{1}{r^{1 / \gamma}(v)} \mathrm{d} v=\eta\left(t, t_{1}\right) U(t) .
\end{aligned}
$$

By a simple computation, we note that

$$
\begin{aligned}
\frac{\mathrm{d}}{\mathrm{d} t}\left(u(t)-\eta\left(t, t_{1}\right) U(t)\right) & =u^{\prime}(t)-\eta^{\prime}\left(t, t_{1}\right) r^{1 / \gamma}(t) u^{\prime}(t)-\eta\left(t, t_{1}\right)\left(r^{1 / \gamma}(t) u^{\prime}(t)\right)^{\prime} \\
& =-\eta\left(t, t_{1}\right) U^{\prime}(t)
\end{aligned}
$$

and

$$
\left(r(t)\left(u^{\prime}(t)\right)^{\gamma}\right)^{\prime}=\frac{\mathrm{d}}{\mathrm{d} t} U^{\gamma}(t)=\gamma U^{\gamma-1}(t) U^{\prime}(t),
$$

which with (2.3) yields

$$
\begin{aligned}
-\eta\left(t, t_{1}\right) U^{\prime}(t) & =-\frac{1}{\gamma} \eta\left(t, t_{1}\right) U^{1-\gamma}(t)\left(r(t)\left(u^{\prime}(t)\right)^{\gamma}\right)^{\prime} \\
& \geq \frac{1}{\gamma} \eta\left(t, t_{1}\right) G(t) U^{1-\gamma}(t) u^{\beta}(\sigma(t)) .
\end{aligned}
$$

Combining (2.5) with (2.6), we get

$$
\frac{\mathrm{d}}{\mathrm{d} t}\left(u(t)-\eta\left(t, t_{1}\right) U(t)\right) \geq \frac{1}{\gamma} \eta\left(t, t_{1}\right) G(t) U^{1-\gamma}(t) u^{\beta}(\sigma(t)) .
$$

Since $r^{\prime}(t) \geq 0$ and $\left(r(t)\left(u^{\prime}(t)\right)^{\gamma}\right)^{\prime} \leq 0$, we have that $u^{\prime \prime}(t) \leq 0$. Thus, from Lemma 1.1, we obtain

$$
u(\sigma(t)) \geq \mu \frac{\sigma(t)}{t} u(t)
$$

for all $t \geq t_{\mu}$. From (2.4), (2.7), and (2.8), we find

$$
\begin{aligned}
\frac{\mathrm{d}}{\mathrm{d} t}\left(u(t)-\eta\left(t, t_{1}\right) U(t)\right) & \geq \frac{\mu^{\beta}}{\gamma} \frac{\sigma^{\beta}(t)}{t^{\beta}} \eta\left(t, t_{1}\right) G(t) U^{1-\gamma}(t) u^{\beta}(t) \\
& =\frac{\mu^{\beta}}{\gamma} \frac{\sigma^{\beta}(t)}{t^{\beta}} \eta\left(t, t_{1}\right) G(t) U^{1-\gamma}(t) u^{\beta-\gamma}(t) u^{\gamma}(t) \\
& \geq \frac{\mu^{\beta}}{\gamma} \frac{\sigma^{\beta}(t)}{t^{\beta}} \eta^{1+\gamma}\left(t, t_{1}\right) G(t) U(t) u^{\beta-\gamma}(t)
\end{aligned}
$$

for $t \geq \max \left\{t_{1}, t_{\mu}\right\}$. Now, since $u(t)$ is positive and increasing, we have that $u(t) \geq u\left(t_{2}\right) \geq$ $m>0$ for $t \geq t_{2} \geq t_{1}$. Moreover, since $r(t)\left(u^{\prime}(t)\right)^{\gamma}$ is positive and decreasing, we see that $r(t)\left(u^{\prime}(t)\right)^{\gamma} \leq r\left(t_{2}\right)\left(u^{\prime}\left(t_{2}\right)\right)^{\gamma}=M$ for $t \geq t_{2}$, and hence

$$
u(t) \leq u\left(t_{2}\right)+M^{1 / \gamma} \eta\left(t, t_{2}\right) .
$$


Since $\eta\left(\infty, t_{1}\right)=\infty$, there exist constant $N>0$ and $t_{N}>t_{\mu}$ such that $\eta\left(t, t_{1}\right)>N$ for all $t \geq t_{N}$. Hence, from (2.10), we find

$$
u(t) \leq K \eta\left(t, t_{2}\right)
$$

where $K:=\left(\frac{1}{N} u\left(t_{2}\right)+M^{1 / \gamma}\right)$. Then we can pick $t_{2} \geq t_{N}$ sufficiently large such that

$$
u^{\beta-\gamma}(t) \geq \begin{cases}\lambda_{1} & \text { if } \gamma<\beta ; \\ 1 & \text { if } \gamma=\beta ; \\ \lambda_{2} \eta^{\beta-\gamma}\left(t, t_{2}\right) & \text { if } \gamma>\beta,\end{cases}
$$

for $t \geq t_{2}$, where $\lambda_{1}=m^{\beta-\gamma}$ and $\lambda_{2}=K^{\beta-\gamma}$. Combining (2.11) with (2.9), we arrive at

$$
\frac{\mathrm{d}}{\mathrm{d} t}\left(u(t)-\eta\left(t, t_{1}\right) U(t)\right) \geq \frac{\mu^{\beta}}{\gamma} \frac{\sigma^{\beta}(t)}{t^{\beta}} \rho(t) \eta^{1+\gamma}\left(t, t_{1}\right) G(t) U(t) .
$$

By integrating this inequality from $t_{2}$ to $t$, we obtain

$$
u(t) \geq \eta\left(t, t_{1}\right) U(t)+\frac{\mu^{\beta}}{\gamma} \int_{t_{2}}^{t} \frac{\sigma^{\beta}(v)}{v^{\beta}} \rho(v) \eta^{1+\gamma}\left(v, t_{1}\right) G(v) U(v) \mathrm{d} v .
$$

From the monotonicity of $U(t)$, we get

$$
u(t) \geq U(t)\left(\eta\left(t, t_{1}\right)+\frac{\mu^{\beta}}{\gamma} \int_{t_{2}}^{t} \frac{\sigma^{\beta}(v)}{v^{\beta}} \rho(v) \eta^{1+\gamma}\left(v, t_{1}\right) G(v) \mathrm{d} v\right) .
$$

This means that

$$
u(\sigma(t)) \geq U(\sigma(t)) \Theta(\sigma(t))
$$

which together with (2.3) implies that

$$
\left(U^{\gamma}(t)\right)^{\prime}+G(t) \Theta^{\beta}(\sigma(t))\left(U^{\gamma}(\sigma(t))\right)^{\beta / \gamma} \leq 0 .
$$

We can see that $v(t)=U^{\gamma}(t)$ is a positive solution of the first order delay differential inequality (2.13). In view of [27, Lemma 1], the associated delay differential equation (2.1) also has a positive solution. This contradiction completes the proof.

Theorem 2.2 If every solution of

$$
v^{\prime}(t)+G(t) \widehat{\Theta}^{\beta}(\sigma(t)) v^{\beta / \gamma}(\sigma(t))=0
$$

oscillates for all $C>0$, then every solution of (1.1) oscillates.

Proof As in the proof of Theorem 2.1, we get that (2.2)-(2.7) hold. Now, we consider the following cases: In the case where $\gamma>\beta$, combining (2.4) with (2.7), we get

$$
\frac{\mathrm{d}}{\mathrm{d} t}\left(u(t)-\eta\left(t, t_{1}\right) U(t)\right) \geq \frac{1}{\gamma} \eta\left(t, t_{1}\right) \eta^{\beta}\left(\sigma(t), t_{1}\right) G(t) U^{1-\gamma}(t) U^{\beta}(\sigma(t)) .
$$


Since $\sigma(t) \leq t$ and $U^{\prime}(t) \leq 0$, we have $U(\sigma(t)) \geq U(t)$, and so

$$
\frac{\mathrm{d}}{\mathrm{d} t}\left(u(t)-\eta\left(t, t_{1}\right) U(t)\right) \geq \frac{1}{\gamma} \eta\left(t, t_{1}\right) \eta^{\beta}\left(\sigma(t), t_{1}\right) G(t) U(t) U^{\beta-\gamma}(t) .
$$

From the fact that $U(t)$ is positive and nonincreasing, we get that $U(t) \leq A$, where $A>0$ and $t \geq t_{2} \geq t_{1}$. Hence, $U^{\beta-\gamma}(t) \geq A^{\beta-\gamma}$ and

$$
\frac{\mathrm{d}}{\mathrm{d} t}\left(u(t)-\eta\left(t, t_{1}\right) U(t)\right) \geq \frac{A^{\beta-\gamma}}{\gamma} \eta\left(t, t_{1}\right) \eta^{\beta}\left(\sigma(t), t_{1}\right) G(t) U(t) .
$$

In the case where $\gamma \leq \beta$, using the facts $u(t)>0$ and $u^{\prime}(t)>0$, we have $u(t) \geq B>0$ for $t$ sufficiently large. It follows from (2.4) and (2.7) that

$$
\begin{aligned}
\frac{\mathrm{d}}{\mathrm{d} t}\left(u(t)-\eta\left(t, t_{1}\right) U(t)\right) & \geq \frac{1}{\gamma} \eta\left(t, t_{1}\right) G(t) U^{1-\gamma}(t) u^{\gamma}(\sigma(t)) u^{\beta-\gamma}(\sigma(t)) \\
& \geq \frac{B^{\beta-\gamma}}{\gamma} \eta\left(t, t_{1}\right) G(t) U^{1-\gamma}(t) u^{\gamma}(\sigma(t)) \\
& \geq \frac{B^{\beta-\gamma}}{\gamma} \eta\left(t, t_{1}\right) \eta^{\gamma}\left(\sigma(t), t_{1}\right) G(t) U^{1-\gamma}(t) U^{\gamma}(\sigma(t)) \\
& \geq \frac{B^{\beta-\gamma}}{\gamma} \eta\left(t, t_{1}\right) \eta^{\gamma}\left(\sigma(t), t_{1}\right) G(t) U(t) .
\end{aligned}
$$

From (2.15) and (2.16), we obtain

$$
\frac{\mathrm{d}}{\mathrm{d} t}\left(u(t)-\eta\left(t, t_{1}\right) U(t)\right) \geq \frac{C^{\beta-\gamma}}{\gamma} \eta\left(t, t_{1}\right) \eta^{\gamma}\left(\sigma(t), t_{1}\right) G(t) U(t),
$$

where $C=\min \{A, B\}$. The rest of the proof is similar to that of Theorem 2.1 and so we omit it.

For the oscillatory behavior of

$$
v^{\prime}(t)+Q(t) v^{\alpha}(\sigma(t))=0
$$

where $Q$ is a positive continuous function, Erbe et al. [15] and Ladde et al. [20] showed that every solution of (2.18) is oscillatory if and only if

$$
\int_{t_{0}}^{\infty} Q(v) \mathrm{d} v=\infty \quad \text { for all } \alpha \in(0,1)
$$

Moreover, Baculikova and Dzurina [6] proved that equation (2.18) is oscillatory if $\alpha \in(0,1]$ and

$$
\liminf _{t \rightarrow \infty} \int_{\sigma(t)}^{t} Q(v) \mathrm{d} v>\frac{1}{\mathbf{e}}
$$

For the case $\alpha>1$, Tang [27] studied the oscillation behavior of (2.18). In the following, by using the results of $[6,15]$, and [27], we obtain new criteria for oscillation of solutions of (1.1). 
Corollary 2.1 Assume that $\gamma>\beta$. If

$$
\int_{t_{0}}^{\infty} G(v) \widehat{\Theta}^{\beta}(\sigma(v)) \mathrm{d} v=\infty,
$$

then every solution of (1.1) oscillates.

Proof From [20], the associated delay differential equation (2.14) is oscillatory if and only if (2.20) holds.

Corollary 2.2 Assume that $\gamma \geq \beta$. If

$$
\liminf _{t \rightarrow \infty} \int_{\sigma(t)}^{t} G(v) \widehat{\Theta}^{\beta}(\sigma(v)) \mathrm{d} v>\frac{1}{\mathbf{e}},
$$

then every solution of (1.1) oscillates.

Proof In view of [6, Lemma 4], the first order delay equation (2.14) is oscillatory if (2.21) holds.

Corollary 2.3 Assume that $\gamma<\beta$. Let there exist a function $\psi \in C^{1}\left(\left[t_{0}, \infty\right), \mathbb{R}\right)$ such that $\psi^{\prime}>0, \lim _{t \rightarrow \infty} \psi(t)=\infty$,

$$
\limsup _{t \rightarrow \infty} \frac{\beta \psi^{\prime}(\sigma(t)) \sigma^{\prime}(t)}{\gamma \psi^{\prime}(t)}<1,
$$

and

$$
\liminf _{t \rightarrow \infty}\left(\frac{1}{\psi^{\prime}(t)} e^{-\psi(t)} G(t) \widehat{\Theta}^{\beta}(\sigma(t))\right)>0
$$

for any $C>0$, then every solution of (1.1) oscillates.

Proof By using the results of [27] in Theorem 1, we get that equation (2.14) is oscillatory if (2.22) holds.

In the next theorem, we use the technique of Riccati to get a new oscillation condition for equation (1.1).

Theorem 2.3 Assume that there exists a function $\varphi \in C^{1}\left(\left[t_{0}, \infty\right),(0, \infty)\right)$ such that

$$
\int_{t_{1}}^{\infty}\left(\varphi(v) \widehat{G}(v)-\frac{r(v)\left(\varphi_{+}^{\prime}(\nu)\right)^{\gamma+1}}{(\gamma+1)^{\gamma+1} \varphi^{\gamma}(\nu)}\right) \mathrm{d} v=\infty
$$

for some sufficiently large $t_{1} \geq t_{0}$, where

$$
\widehat{G}(t):=G(t) \rho(t) \exp \left(-\gamma \int_{\sigma(t)}^{t} \frac{1}{r^{1 / \gamma}(v) \Theta(v)} \mathrm{d} v\right)
$$

and $\varphi_{+}^{\prime}(t)=\max \left\{\varphi^{\prime}(t), 0\right\}$, then every solution of $(1.1)$ oscillates. 
Proof As in the proof of Theorem 2.1, we get (2.2)-(2.12) hold. From (2.12), we deduce that

$$
\frac{u^{\prime}(t)}{u(t)} \leq \frac{1}{r^{1 / \gamma}(t) \Theta(t)}
$$

By integrating this inequality from $\sigma(t)$ to $t$, we get

$$
u(\sigma(t)) \geq u(t) \exp \left(-\int_{\sigma(t)}^{t} \frac{1}{r^{1 / \gamma}(\nu) \Theta(\nu)} \mathrm{d} v\right)
$$

Now, we define the following function:

$$
R(t):=\varphi(t) r(t)\left(\frac{u^{\prime}(t)}{u(t)}\right)^{\gamma}, \quad t \geq t_{1}
$$

Then we have

$$
R^{\prime}(t)=\frac{\varphi^{\prime}(t)}{\varphi(t)} R(t)+\varphi(t)\left(\frac{\left(r(t)\left(u^{\prime}(t)\right)^{\gamma}\right)^{\prime}}{u^{\gamma}(t)}-\gamma r(t)\left(\frac{u^{\prime}(t)}{u(t)}\right)^{\gamma+1}\right) .
$$

By (2.3) and (2.11), we deduce that

$$
\begin{aligned}
\frac{\left(r(t)\left(u^{\prime}(t)\right)^{\gamma}\right)^{\prime}}{u^{\gamma}(t)} & \leq-G(t) \frac{u^{\beta}(\sigma(t))}{u^{\gamma}(t)} \\
& =-G(t) \frac{u^{\gamma}(\sigma(t))}{u^{\gamma}(t)} u^{\beta-\gamma}(\sigma(t)) \\
& \leq-G(t) \rho(t) \exp \left(-\gamma \int_{\sigma(t)}^{t} \frac{1}{r^{1 / \gamma}(v) \Theta(v)} \mathrm{d} v\right) \\
& =-\widehat{G}(t) .
\end{aligned}
$$

By the definition (2.25), we obtain

$$
\left(\frac{u^{\prime}(t)}{u(t)}\right)^{\gamma+1}=\frac{1}{r^{1+1 / \gamma}(t) \varphi^{1+1 / \gamma}(t)} R^{1+1 / \gamma}(t) .
$$

From (2.26)-(2.28), we find

$$
R^{\prime}(t) \leq-\varphi(t) \widehat{G}(t)+\frac{\varphi^{\prime}(t)}{\varphi(t)} R(t)-\frac{\gamma}{r^{1 / \gamma}(t) \varphi^{1 / \gamma}(t)} R^{1+1 / \gamma}(t) .
$$

Next, by using Lemma 1.2 with $k=\varphi_{+}^{\prime} / \varphi, l=\gamma r^{-1 / \gamma} \varphi^{-1 / \gamma}$ and $s=R$, we have

$$
R^{\prime}(t) \leq-\varphi(t) \widehat{G}(t)+\frac{r(t)\left(\varphi_{+}^{\prime}(t)\right)^{\gamma+1}}{(\gamma+1)^{\gamma+1} \varphi^{\gamma}(t)}
$$

Integrating the latter inequality from $t_{1}$ to $t$, we get

$$
\int_{t_{1}}^{t}\left(\varphi(v) \widehat{G}(v)-\frac{r(v)\left(\varphi_{+}^{\prime}(v)\right)^{\gamma+1}}{(\gamma+1)^{\gamma+1} \varphi^{\gamma}(v)}\right) \mathrm{d} v \leq R\left(t_{1}\right)-R(t) \leq R\left(t_{1}\right)
$$

which contradicts (2.23). Therefore, equation (1.1) is oscillatory. 
Example 2.1 Consider the equation

$$
\left(\left[\left(y(t)+p_{0} y(\delta t)\right)^{\prime}\right]^{\gamma}\right)^{\prime}+\frac{q_{0}}{t^{(\gamma+3) / 2}} y(\lambda t)=0,
$$

where $t>0, \gamma \geq 1$ is a quotient of odd positive integers, $\beta=1, p_{0} \in[0,1), \delta, \lambda \in(0,1]$, and $q_{0}>0$. By using Theorem 2.2, we get that equation (2.29) is oscillatory if every solution of

$$
v^{\prime}(t)+\phi(t) v^{1 / \gamma}(\lambda t)=0
$$

oscillates, where

$$
\phi(t):=q_{0}\left(1-p_{0}\right)\left(\frac{\lambda}{t^{(\gamma+1) / 2}}+q_{0}\left(1-p_{0}\right) \lambda^{(3 \gamma+1) / 2} \frac{2 C^{1-\gamma}}{\gamma(\gamma+1)} \frac{1}{t}\right)
$$

for all $C>0$.

By Corollary 2.1, if $\gamma>1$, then

$$
\int_{t_{0}}^{\infty} \phi(v) \mathrm{d} v=\infty
$$

and hence equation (2.29) is oscillatory. Obviously, the results of Baculikova and Dzurina in [6] fail to apply on this equation.

Let $\gamma=1$. From Corollary 2.2, we obtain that equation (2.29) is oscillatory if

$$
q_{0}\left(1-p_{0}\right)\left(\lambda+q_{0}\left(1-p_{0}\right) \lambda^{2}\right) \ln \frac{1}{\lambda}>\frac{1}{\mathbf{e}} .
$$

As a special case of equation (2.29), the equation

$$
\left(y(t)+\frac{1}{2} y\left(\frac{1}{2} t\right)\right)^{\prime \prime}+\frac{q_{0}}{t^{2}} y\left(\frac{1}{3} t\right)=0
$$

is oscillatory if $q_{0}>1.58856$. By applying Corollary 2 in [6], the known related criterion for (2.30) is $q_{0}>5.44381$. On the other hand, equation (2.30) has nonoscillatory solution $y(t):=\sqrt{t}$ when

$$
q=\frac{\sqrt{3}}{16}(4+\sqrt{2})<1.58856
$$

Example 2.2 Consider the equation

$$
\left(y(t)+\frac{1}{2} y(\delta t)\right)^{\prime \prime}+\frac{q_{0}}{t^{2}} y(\lambda t)=0,
$$

where $t>0$ and $\delta, \lambda \in(0,1]$, the known related criteria for oscillation of this equation are as follows:

1. By applying Corollary 2 in [6],we get

$$
q_{0} \lambda \ln \frac{1}{2 \lambda}>\frac{2}{\mathrm{e}} ;
$$




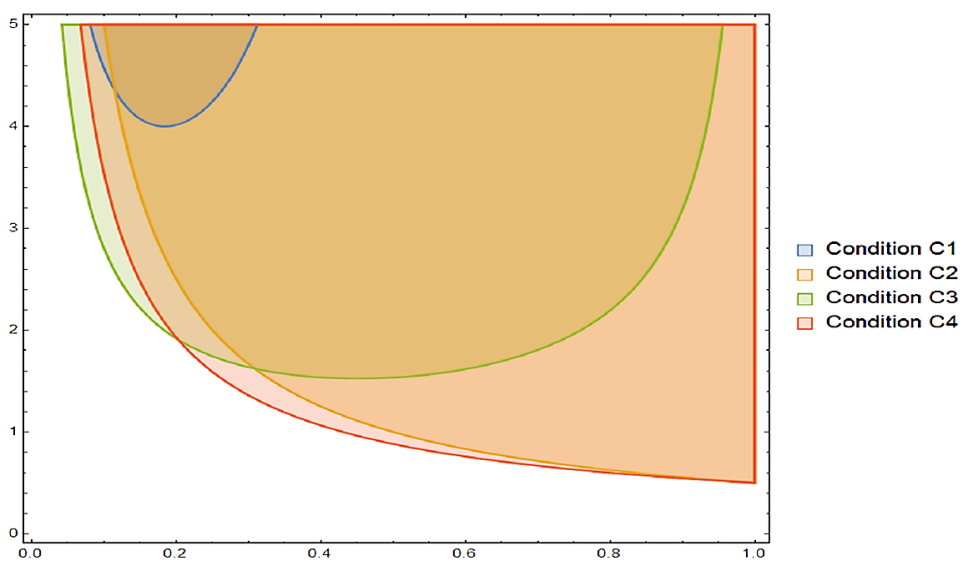

Figure 1 Regions for which Conditions (C1)-(C4) are satisfied

2. By applying Theorem 1 in [28] or Theorem 2.1 in [23],we obtain

$$
q_{0} \lambda>\frac{1}{2}
$$

3. By applying our results in Corollary 2.2, we have

$$
\frac{1}{2} q_{0} \lambda\left(1+\frac{1}{2} \lambda q_{0}\right) \ln \frac{1}{\lambda}>\frac{1}{\mathrm{e}}
$$

4. By applying our results in Theorem 2.3, we find

$$
q_{0} \lambda^{1 /\left(1+\lambda q_{0} / 2\right)}>\frac{1}{2}
$$

In Fig. 1, we test the strength of oscillation criteria (C1)-(C4).

Remark 2.1 From the previous examples, we note that:

- By using the technique of comparison with first order delay equations, Corollary 2.1 improves Corollary 2 in [6].

- Based on the technique of Riccati transformation, Theorem 2.3 improves Theorem 1 in [28] and Theorem 2.1 in [23].

- Condition (C3) supports the most efficient condition for values of $\lambda \in(0,0.2)$, and Condition (C4) supports the most efficient condition for values of $\lambda \in(0.2,1)$.

Acknowledgements

The authors present their sincere thanks to the editors and two anonymous referees. In fact, the observations were very important and contributed significantly to the improvement of the final version of the paper.

Funding

For this paper, no direct funding.

Availability of data and materials

No data sharing (where no datasets are produced). 
Authors' contributions

This article has one author, which read and approved the final manuscript.

\section{Publisher's Note}

Springer Nature remains neutral with regard to jurisdictional claims in published maps and institutional affiliations.

Received: 9 August 2019 Accepted: 13 November 2019 Published online: 21 November 2019

\section{References}

1. Agarwal, R.P., Grace, S.R., O'Regan, D.: Oscillation Theory for Second Order Linear, Half-Linear, Superlinear and Sublinear Dynamic Equations. Kluwer Academic, Dordrecht (2002)

2. Agarwal, R.P., Grace, S.R., O'Regan, D.: Oscillation Theory for Second Order Dynamic Equations. Taylor \& Francis, London (2003)

3. Agarwal, R.P., Zhang, C., Li, T.: Some remarks on oscillation of second order neutral differential equations. Appl. Math. Comput. 274, 178-181 (2016)

4. Baculikova, B.: Oscillatory behavior of the second order functional differential equations. Appl. Math. Lett. 72, 35-41 (2017)

5. Baculikova, B., Dzurina, J.: Oscillation of third-order neutral differential equations. Math. Comput. Model. 52, 215-226 (2010)

6. Baculikova, B., Dzurina, J.: Oscillation theorems for second-order nonlinear neutral differential equations. Comput. Math. Appl. 62(12), 4472-4478 (2011)

7. Bainov, D.D., Mishev, D.P.: Oscillation Theory for Neutral Differential Equations with Delay. Hilger, New York (1991)

8. Bazighifan, O., Elabbasy, E.M., Moaaz, O.: Oscillation of higher-order differential equations with distributed delay. J. Inequal. Appl. 2019, 55 (2019)

9. Bohner, M., Grace, S.R., Jadlovska, I.: Oscillation criteria for second-order neutral delay differential equations. Electron. J. Qual. Theory Differ. Equ. 2017, 60 (2017)

10. Bohner, M., Grace, S.R., Sager, I., Tunc, E.: Oscillation of third-order nonlinear damped delay differential equations. Appl. Math. Comput. 278, 21-32 (2016)

11. Chatzarakis, G.E., Dzurina, J., Jadlovska, I.: New oscillation criteria for second-order half-linear advanced differential equations. Appl. Math. Comput. 347, 404-416 (2019)

12. Chatzarakis, G.E., Dzurina, J., Jadlovska, I.: A remark on oscillatory results for neutral differential equations. Appl. Math. Lett. 90, 124-130 (2019)

13. Chatzarakis, G.E., Jadlovska, l.: Improved oscillation results for second-order half-linear delay differential equations. Hacet. U. Bull. Nat. Sci. Eng. Series B 47(6) (2017)

14. Elabbasy, E.M., Hassan, T.S., Moaaz, O.: Oscillation behavior of second order nonlinear neutral differential equations with deviating arguments. Opusc. Math. 32, 719-730 (2012)

15. Erbe, L.H., Kong, Q., Zhang, B.G.: Oscillation Theory for Functional Differential Equations. Dekker, New York (1995)

16. Grace, S.R., Dzurina, J., Jadlovska, I., Li, T.: An improved approach for studying oscillation of second-order neutral delay differential equations. J. Inequal. Appl. 2018, 193 (2018)

17. Grace, S.R., Graef, J.R., Tunc, E.: Oscillatory behavior of second order damped neutral differential equations with distributed deviating arguments. Miskolc Math. Notes 18(2), 759-769 (2017)

18. Graef, J.R., Grace, S.R., Tunc, E.: Oscillation of even-order advanced functional differential equations. Publ. Math. (Debr.) 93(3-4), 445-455 (2018)

19. Graef, J.R., Grace, S.R., Tunc, E.: Oscillatory behavior of even-order nonlinear differential equations with a sublinear neutral term. Opusc. Math. 39(1), 39-47 (2019)

20. Ladde, G.S., Lakshmikantham, V., Zhang, B.G.: Oscillation Theory of Differential Equations with Deviating Arguments. Dekker, New York (1987)

21. Li, T., Han, Z., Zhao, P., Sun, S.: Oscillation of even-order neutral delay differential equations. Adv. Differ. Equ. 2010, Article ID $184180(2010)$

22. Li, T., Rogovchenko, Y.V., Zhang, C.: Oscillation results for second-order nonlinear neutral differential equations. Adv. Differ. Equ. 2013, 336 (2013)

23. Liu, H., Meng, F., Liu, P.: Oscillation and asymptotic analysis on a new generalized Emden-Fowler equation. Appl. Math. Comput. 219, 2739-2748 (2012)

24. Moaaz, O., Elabbasy, E.M., Bazighifan, O.: On the asymptotic behavior of fourth-order functional differential equations. Adv. Differ. Equ. 2017, 261 (2017)

25. Moaaz, O., Elabbasy, E.M., Muhib, A.: Oscillation criteria for even-order neutral differential equations with distributed deviating arguments. Adv. Differ. Equ. 2019, 297 (2019)

26. Moaaz, O., Elabbasy, E.M., Shaaban, E.: Oscillation criteria for a class of third order damped differential equations. Arab J. Math. Sci. 24(1), 16-30 (2018)

27. Tang, X.H.: Oscillation for first order superlinear delay differential equations. J. Lond. Math. Soc. 65(2), 115-122 (2002)

28. $\mathrm{Wu}$, Y., Yu, Y., Zhang, J., Xiao, J.: Oscillation criteria for second order Emden-Fowler functional differential equations of neutral type. Appl. Math. Comput. 219, 2739-2748 (2012)

29. Xing, G., Li, T., Zhang, C.: Oscillation of higher-order quasi-linear neutral differential equations. Adv. Differ. Equ. 2011, $45(2011)$

30. Zeng, Y.H., Lou, L.P., Yu, Y.H.: Oscillation for Emden-Fowler delay differential equations of neutral type. Acta Math. Sci. 35A, 803-814 (2015) 